ARTIGO DE REVISÃO

\title{
Síndrome do QT Longo
}

\section{Long QT Syndrome}

Roseli Guiomar Batista Nogueira ${ }^{[a]}$, Eduardo Santos Rebello ${ }^{[b]}$, Ana Paula Santos Rebello ${ }^{[c]}$, Vanessa Santos Sotomaior ${ }^{[\mathrm{d}]}$, Salmo Raskin ${ }^{[\mathrm{e}]}$

\section{Resumo}

A Síndrome do QT longo (SQTL) é uma doença caracterizada pela demora na repolarização ventricular. Essa síndrome manifesta-se clinicamente como síncope cardíaca e morte súbita causadas por uma forma atípica de taquicardia ventricular polimórfica conhecida como torsade de pointes (TdP). A síncope ocorre, principalmente, durante a prática de exercícios físicos ou por uma carga emocional intensa, e, menos frequentemente, durante o sono. Mais de 500 mutações associadas à SQTL foram descritas em 10 genes diferentes. Eles se encontram nos cromossomos 11p15.5 (LQT1), 7q35-36 (LQT2), 3p2124 (LQT3), 4q25-27 (LQT4), 21q22.1 (LQT5), 21q22.1 (LQT6), 17q23 (LQT7), 12p13.3 (LQT8), 3p25 (LQT9) e 11q23 (LQT10). 0 genótipo influencia diretamente 0 curso clínico da doença. Beta-bloqueador, desfibrilador automático e cirurgia de denervação cardíaca são utilizados para prevenir a taquicardia ventricular. A compreensão dos mecanismos moleculares envolvidos na SQTL tem permitido o estabelecimento de correlações genótipo-fenótipo-tratamento, que contribuem para uma melhor qualidade de vida e maior sobrevida dos pacientes. Esta revisão apresenta as características clínicas, moleculares e epidemiológicas desta síndrome.

Palavras-chave: Síndrome do QT longo. SQTL. Torsade de pointes. Canais iônicos.

\begin{abstract}
Long QT syndrome (LQTS) is a disorder characterized by delayed ventricular repolarization. The condition is associated with sudden cardiac syncope and death due to polymorphic ventricular tachycardia known as torsade de pointes (TdP). Syncope typically occurs during exercise and high emotional load, occurring less frequently at rest or during sleep, and usually without warning. Over 500 mutations in 10 gene have been associated with LQTS in chromosomes 11p15.5 (LQT1), 7q35-36 (LQT2), 3p21-24 (LQT3), 4q25-27 (LQT4), 21q22.1 (LQT5), $21 q 22.1$ (LQT6), 17q23 (LQT7), 12p13.3 (LQT8), 3p25 (LQT9) and 11q23 (LQT10). The genotype of the long QT syndrome influences the clinical course. Beta-adrenergic blockade, sympathetic denervation of the heart and automatic defibrillator are used to prevent ventricular dysrhythmia. Understanding of the molecular processes underlying the syndrome is enabling correspondence between genotype, phenotype and therapy to be established and is leading to better quality of life and survival among sufferers. This review explores the clinical, molecular and epidemiological features of this syndrome.
\end{abstract}

Keywords: Long QT syndrome. SQTL. Torsade de pointes. Ionic channels.
${ }^{[a]}$ Bióloga pela Pontifícia Universidade Católica do Paraná (PUCPR), Curitiba, PR - Brasil, e-mail: roselinogueira@yahoo.com.br

${ }^{[b]}$ Especialista em Genética Humana pela Pontifícia Universidade Católica do Paraná (PUCPR), Curitiba, PR - Brasil, e-mail: eduardorebello@pop.com.br

${ }^{[c]}$ Bióloga pela Universidade Positivo (UTP), Curitiba, PR - Brasil, e-mail: anapaularebello@yahoo.com.br

${ }^{[\mathrm{dd}]}$ Doutora em Biologia Celular e Molecular pelo Instituto Oswaldo Cruz (FIOCRUZ), Rio de Janeiro, RJ - Brasil, e-mail: sotomaior@onda.com.br

${ }^{[e]}$ Doutor em Genética pela Universidade Federal do Paraná (UFPR) Curitiba, PR - Brasil, e-mail: genetika@genetika.com.br
Recebido: 25/09/2009

Received: 09/25/2009

Aprovado: 14/10/2010

Approved: 10/14/2010 


\section{Argumentações}

A atividade cardíaca normal é dependente da propagação ordenada de impulsos elétricos por meio do miocárdio, a qual é resultado da alternância de concentrações de ions específicos. Alterações nos canais transportadores desses íons podem levar a distúrbios letais do ritmo cardíaco, tais como os observados na Síndrome do QT Longo (SQTL) (1).

A SQTL, uma doença cardiovascular hereditária, é caracterizada por alterações nos canais iônicos de sódio $\left(\mathrm{Na}^{+}\right)$e potássio $\left(\mathrm{K}^{+}\right)$causadas por mutações em genes que codificam as proteínas de membrana. Tais mutações geram uma anormalidade na repolarização cardíaca que pode ser observada no eletrocardiograma (ECG) por um prolongamento do intervalo QT (2).

Os primeiros casos dessa síndrome foram descritos em 1856, por Meissner, na Alemanha, em que três crianças de uma mesma família sofreram morte súbita durante um estresse emocional (3). Mais tarde, em 1901, Morquio identificou uma grande família com essa síndrome, o que indicava uma provável origem genética (4). Em 1957, Jervell e Lange-Nielsen descreveram outra família em que quatro crianças, num conjunto de dez, possuíam surdez e recorrência de síncopes durante exercícios físicos ou emoção. Três crianças morreram subitamente com idades de 4, 5 e 9 anos. Uma síndrome clinicamente similar, porém com audição normal, foi descrita em 1963 por Romano (5) e em 1964 por Ward (6).

Entre os casos diagnosticados de SQTL, 99\% são do tipo Romano-Ward e menos de 1\% corresponde ao tipo Jervell-Lange-Nielsen. A SQTL afeta todos os grupos étnicos, mas é desconhecido se a prevalência é a mesma em todos esses grupos (3). A SQTL apresenta-se, geralmente, na forma monogênica e as variedades poligênicas ou compostas constituem fenótipos mais graves (7).

A Síndrome de Romano-Ward é herdada geralmente de maneira autossômica dominante, porém pode ser transmitida de forma recessiva (7). Ela está associada a alterações nos canais de $\mathrm{K}^{+}$e $\mathrm{Na}^{+}$, sendo que os indivíduos afetados apresentam audição normal. Mais de 500 mutações em diferentes genes foram descritas causando esta síndrome, que ocorre em aproximadamente 1:5000 indivíduos. Nos Estados Unidos, de três a quatro mil casos de morte súbita de crianças e jovens são registrados por ano (8) e, na Noruega, pesquisas revelaram que 9,5\% das crianças vítimas desse tipo de morte possuem mutações nos genes associados à SQTL (9).
Já a Síndrome de Jervell-Lange-Nielsen é transmitida de modo autossômico recessivo, os pais são heterozigotos, apresentam enfermidade menos grave ou são assintomáticos e, ao contrário da forma Romano-Ward, está relacionada apenas aos canais de $\mathrm{K}^{+}$e apresenta surdez sensorioneural (7).

As manifestações clínicas da SQTL incluem episódios de síncopes, frequentemente resultando em parada cardíaca e morte súbita. Essas síncopes se devem a taquicardias ventriculares (torsades de pointes ou TdP) que podem ser demonstradas no ECG quando o intervalo QT é maior que 0,66s (10). Segundo Domingo (7), o intervalo QT é medido do início do QRS até o fim da onda $\mathrm{T}$ e deve ser corrigido pela frequência cardíaca, utilizando a fórmula de Bazzet $(\mathrm{QTc}=\mathrm{QT} / \sqrt{\mathrm{RR}})$.

As síncopes são mais frequentes em pacientes com idade inferior a 20 anos (11) e o risco de um indivíduo com mais de 40 anos apresentar morte súbita é de aproximadamente 4\% (12). Pacientes do sexo masculino possuem, normalmente, QTc $<440$ $\mathrm{ms}$, contrariamente ao sexo oposto que apresenta QTc $<460 \mathrm{~ms}$, ou seja, o sexo feminino tem maior predisposição a desenvolver sintomas cardíacos, por apresentar naturalmente um intervalo QT maior (12). Tem-se observado que o risco de apresentar arritmias ventriculares malignas diminui durante a gestação, porém, nos meses posteriores ao parto, tem-se comunicado um aumento na vulnerabilidade da mulher em apresentar tais arritmias, principalmente na SQTL2 (7).

Há dez tipos de SQTL, até o momento (Tabela 1), de acordo com o gene mutado: tipo 1 relacionado ao gene $K C N Q 1$, localizado no cromossomo 11; tipo 2 relacionado ao gene $K C N H 2$, localizado no cromossomo 7; tipo 3 relacionado ao gene SCN5A, localizado no cromossomo 3; tipo 4 relacionado ao gene $A N K 2$, localizado no cromossomo 4; os tipos 5 e 6 são relacionados aos genes KCNE1 e KCNE2, respectivamente, ambos localizados no cromossomo 21; tipo 7 relacionado ao gene $K C N J 8$, localizado no cromossomo 17; tipo 8 relacionado ao gene CACNA1, localizado no cromossomo 12; tipo 9 relacionado ao gene $C A V 3$, localizado no cromossomo 3; e tipo 10 relacionado ao gene $S C N 4 B$, localizado no cromossomo 11. Apesar dos estudos na última década, aproximadamente $25 \%$ a $30 \%$ dos casos não apresentam mutação nos genes descritos anteriormente e os pacientes permanecem sem diagnóstico genético. Esta é uma das razões pelas quais a SQTL continua sendo motivo de investigação (13). 
Tabela 1 - Genes envolvidos na SQTL

\begin{tabular}{|c|c|c|c|c|c|}
\hline Subtipos & Lócus & Gene & Proteína & Corrente & $\begin{array}{c}\text { Frequência (\%) } \\
\text { aproximada }\end{array}$ \\
\hline \multicolumn{6}{|c|}{ Romano-Ward (autossômica dominante) } \\
\hline SQTL1 & $11 \mathrm{p} 15.5$ & KCNQ1/KVLQT1 & Subunidade $a \mathrm{I}_{\mathrm{ks}}$, Principal & $\mathrm{K}$ & 48 \\
\hline SQTL2 & $7 q 35-36$ & KCNH2-HERG & Subunidade $\alpha I_{k r}$, Principal & $\mathrm{K}$ & 40 \\
\hline SQTL3 & $3 p 21-p 24$ & SCN5A & Subunidade $a I_{\mathrm{Na}}$, Principal & $\mathrm{I}_{\mathrm{Na}}$ & 9 \\
\hline SQTL4 & $4 q 25-q 27$ & $A N K B$ & Anquirina- $B$, Acessória & $\mathrm{Na}-\mathrm{Ca}$ & 1 \\
\hline SQTL5 & $21 \mathrm{q} 22.1$ & KCNE1-mink & Subunidade $B I_{k s}$, Acessória & K & 3 \\
\hline SQTL6 & $21 \mathrm{q} 22.1$ & KCNE2-MIRP1 & Subunidade $B I_{k r}$, Acessória & $\mathrm{K}$ & 2 \\
\hline SQTL7a & $17 q 23$ & KCNJ8 & Subunidade a Kir 2.1, Principal & $\mathrm{K}$ & 1 \\
\hline SQTL8 $8^{\mathrm{b}}$ & $12 \mathrm{p} 13.3$ & CACNA1 & Subunidade $a \mathrm{Ca}_{v} 1.2$, Principal & Ca tipo $L$ & 0,5 \\
\hline SQTL9 & $3 p 25$ & CAV3 & Caveolina 3, Acessória & $\mathrm{Na}$ & 1 \\
\hline SQTL10 & $11 q 23$ & SCN4B & Subunidade $\mathrm{B} 4 \mathrm{I}_{\mathrm{Na}}$, Acessória & $\mathrm{Na}$ & 0,5 \\
\hline \multicolumn{6}{|c|}{ Jervell-Lange-Nielsen (autossômica recessiva) } \\
\hline JLN1 & $11 \mathrm{p} 15.5$ & KCNQ1-KVLQT1 & Subunidade $a \mathrm{I}_{\mathrm{ks}}$, Principal & $\mathrm{K}$ & 90,5 \\
\hline JLN2 & $21 \mathrm{q} 22.1$ & KCNE1-mink & Subunidade $B I_{k s}$, Acessória & K & 0,5 \\
\hline
\end{tabular}

Fonte: Domingo et al. (7)

a Síndrome de Andersen-Tawil.

bSíndrome de Timothy.

A SLQT1 é o tipo mais frequente, acometendo $42 \%$ a $55 \%$ dos pacientes com SQTL. Manifesta-se com episódios de arritmias ventriculares (AV) em exercícios, especialmente durante a natação, ou estímulo do simpático; a SLQT2 exprime-se em 35\% a $45 \%$ dos casos, apresenta susceptibilidade a AV mediadas por estresse emocional, estímulos auditivos e também são constantes no período pós-parto, manifestando-se com menos frequência durante o sono e exercícios; a SLQT3 acomete de $8 \%$ a $10 \%$ dos pacientes e revela-se por arritmias malignas durante o repouso ou bradicardia; a SQTL4 está presente em aproximadamente $1 \%$ dos casos, é clinicamente muito atípica e apresenta-se com taquicardia ventricular polimórfica catecolaminérgica, fibrilação atrial, transtornos na condução intraventricular, disfunção do nódulo sinusal e bradicardia; a SLQT5 e a SQTL6 são pouco caracterizadas, representando $3 \%$ e $2 \%$ dos casos respectivamente; a SQTL7, considerada uma manifestação da Síndrome de Andersen-Tawil (SAT1), apresenta um quadro clínico de desenvolvimento esquelético anormal, paralisia osteomuscular, extrassístoles ventriculares, taquicardia ventricular polimórfica, taquicardia ventricular bidirecional e TdP; a SQTL8, representada por menos de $0,5 \%$ dos casos descritos, é uma manifestação da Síndrome de Timothy e caracteriza-se por má formações cardíacas, deficiência imunológica, hipoglicemia intermitente, transtorno cognitivos (autismo), fusões interdigitais (mãos e pés), predisposição para arritmias cardíacas e morte súbita; a SQTL9 está presente em menos de 1\% dos casos e possui fenótipo similar aos tipos SQTL3 e SQTL10, sendo ainda pouco caracterizada (7) (Gráfico 1).

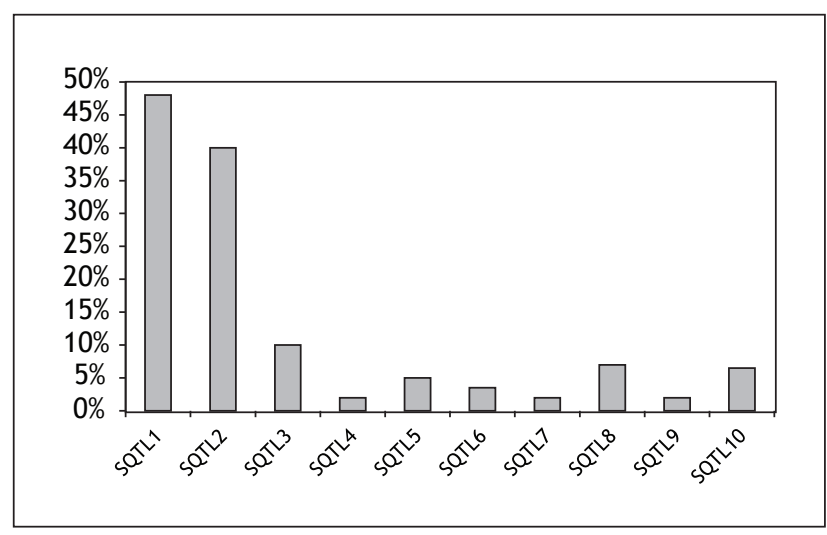

Gráfico 1 - Frequência de pacientes afetados pelos diferentes subtipos de SQTL

Fonte: Domingo et al. (7) 
0 primeiro gene estudado, associado à SQTL, é o KCNQ1, que está localizado em 11p15.5 (14) e codifica a subunidade $\alpha$ maior do canal Iks (de ativação lenta), contendo 676 aminoácidos (15). 0 gene KCNQ1 é constituído por 19 éxons e estende-se por mais de $400 \mathrm{~kb}(16)$.

0 segundo gene descrito é o $K C N H 2$, localizado em 7q35-36 (17) e formado por 15 éxons, possuindo 19 kb (18). Codifica uma proteína de 1.159 aminoácidos, com terminações carboxi e amino extensas, que formam a subunidade $\alpha$ menor do canal $\mathrm{K}^{+}(19)$. Mais de 145 mutações foram identificadas nesse gene, sendo que algumas mutações são nas regiões dos domínios externos e outras nas regiões do canal.

O terceiro gene é o $S C N 5 A$, localizado em 3 p21 (20) e que codifica uma proteína do canal de $\mathrm{Na}^{+}$formada por 2.016 aminoácidos (21). Possui 28 éxons (22), sendo que 33 mutações e 34 polimorfismos foram descritos nesse gene, aproximadamente.

0 quarto gene, localizado em $4 q 25-27$, é denominado de $A N K 2$ por codificar a anquirina- $\beta$, uma proteína estrutural que conecta as proteínas de membrana das células cardíacas às proteínas do citoesqueleto (23).

0 gene KCNE1 possui $40 \mathrm{~kb}$, distribuídos em 3 éxons e 2 íntrons e codifica a subunidade $\beta$ do canal $\mathrm{K}^{+}$ (24). Está localizado em 21q22.1 (25).

0 sexto gene descrito é $K C N E 2$, localizado em 21q22, codifica uma pequena proteína de 127 aminoácidos similar em tamanho e função àquela resultante do gene KCNE1 (26). Três mutações já foram descritas nesse gene.

Pouco se conhece a respeito dos quatro últimos genes descritos na literatura. 0 KCNJ8, localizado em 17q23, codifica o canal retificador de $\mathrm{K}^{+}$, Kir 2.1. o CACNA1 está localizado em 12 p13.3 e codifica a subunidade $\alpha$ do canal de cálcio. 0 gene CAV3, localizado em 3p25, codifica a caveolina, proteína especialmente expressa em cardiomiócitos e no músculo esquelético que auxilia na transdução de sinais dessas células. 0 último gene descrito até o momento $(S C N 4 B)$ codifica a subunidade $\beta$ que interage e regula as diversas isoformas de canal de $\mathrm{Na}^{+}$. Esse gene encontra-se em 11q23 (27).

Análise estatística realizada por Schwartz (28) mostrou diferentes frequências para os eventos que desencadeiam a SQTL1, SQTL2 e SQTL3, os tipos mais frequentes de SQTL. Na SQTL1, 62\% dos eventos de síncope e morte súbita são associados com exercício, $26 \%$ com emoção e somente $3 \%$ com descanso e sono. Por outro lado, somente $13 \%$ dos pacientes com
SQTL3 tiveram eventos cardíacos durante exercício e 39\% durante sono e descanso. Padrão intermediário observa-se na SQTL2, com 13\% dos eventos ocorrendo durante exercício e $43 \%$ em estresse emocional. Adicionalmente, a letalidade dos eventos são maiores na SQTL3 e SQTL2 comparando-se com a SQTL1. Muitos dos eventos letais estão associados ao exercício físico: 68\% na SQTL1, 4\% na SQTL3 e 0\% SQTL2.

Além dos eventos cardiológicos da Síndrome de Romano-Ward serem desencadeados por diversos fatores de acordo com o gene mutado, algumas drogas como a Amiodarona, que é um potente antiarrítmico, podem prolongar o intervalo QT em humanos, graças aos seus efeitos inibitórios na corrente de $\mathrm{Na}^{+}, \mathrm{K}^{+} \mathrm{e}$ $\mathrm{Ca}^{+}$no coração. 0 Cisapride, uma droga pro-cinética que tem um potencial moderado, mesmo em doses pequenas, pode produzir uma prolongação do QT por aumentar a repolarização, preferencialmente, nas células M ou endocárdicas (8). Antidepressivos tricíclicos também são relevantes no prolongamento das ondas QT, em função da possibilidade dos psicotrópicos causarem alterações nas propriedades elétricas dos cardiomiócitos (29).

O diagnóstico da SQTL é extremamente complexo, pois nem sempre as manifestações da doença são evidentes. Entretanto baseia-se nas características clínicas do paciente, histórico familiar e achados eletrocardiográficos e ecográficos (30). O ECG é realizado para verificar possíveis distúrbios no intervalo QT ou arritmias, enquanto que o ecocardiograma é utilizado para verificar o aumento do grau de espessamento do coração no momento da contração (31).

0 teste diagnóstico definitivo é realizado por meio de exames genéticos, nos quais são pesquisados os genes responsáveis pela SQTL que, quando mutados, podem proporcionar o aparecimento da irregularidade eletrocardiográfica (2). Entretanto, aproximadamente $30 \%$ dos pacientes que possuem sinais clínicos da Síndrome de Romano-Ward não apresentam mutações nas regiões codificadoras de nenhum dos genes até agora identificados já associados à SQTL (32). Atualmente, pesquisadores estão buscando outros genes causadores e incluindo nos estudos as regiões não codificadoras dos genes já descritos (9). Em estudos genéticos post morte ou autópsia molecular, constata-se SQTL em $10 \%$ e $30 \%$ nas mortes súbitas infantil e juvenil, respectivamente. Tais testes são importantes para avaliar o risco de SQTL para os demais membros da família e indicar o aconselhamento genético (7). 
O tratamento da SQTL varia de acordo com o tipo clínico e a mutação. Para pacientes com os tipos 1 e 2 , beta-bloqueadores são administrados várias vezes ao dia, os quais se ligam aos canais de $\mathrm{K}^{+}$impedindo episódios de síncope e arritmias (33). Para pacientes com o tipo 3, utiliza-se a implantação de marcapasso (34), desfibrilador cardíaco automático (35) ou cirurgia de denervação cardíaca (36). Os beta-bloqueadores devem ser administrados com cautela, pois os episódios de arritmias ventriculares são mais comuns com frequência cardíaca baixa (7). Para estabelecer as doses adequadas da medicação mencionada é útil a prova do esforço.

No Brasil, há necessidade de centros destinados aos estudos genéticos de enfermidades cardíacas que disponibilizem testes à população em geral, incluindo os mais carentes, detectando a patologia que nem sempre se apresenta clara em exames clínicos. A criação e manutenção, inicialmente, de dois centros no país, a partir da prestação dos seus serviços à população já seriam um grande avanço para a melhoria da qualidade de vida desses pacientes. Tais iniciativas poderiam ser governamentais e/ou privadas.

\section{Referências}

1. Shah M, Akar FG, Tomaselli GF. Molecular basis of arrhythmias. Circulation. 2005;112(16):2517-29.

2. Splawski I, Shen J, Timothy KW, Lehmann MH, Priori S, Robinson JL, et al. Spectrum of mutations in long-QT syndrome genes: KVLQT1, HERG, SCN5A, KCNE1, and KCNE2. Circulation. 2000;102(10):1178-85.

3. Vincent GM. Long QT syndrome. Cardiol Clin. 2000; 18(2):309-25.

4. Oliveira NA Jr., Andréa EM, Maciel WA, de Siqueira LR, Atié J, Cosenza R. 0 eletrocardiograma e a síndrome do QT longo. Revista da SOCERJ. 2004;17(3):177-82.

5. Romano C, Gemme G, Pongiglione R. Aritmie cardiache rare dell' eta pediatrica. II. Accessi sincopali per fibrillazione ventricolare parossistica. Clin Pediat. 1963;45:656-83.

6. Ward OC. A new familial cardiac syndrome in childr. J Ir Med Assoc. 1964;54:103-6.

7. Domingo A, Iturralde-torres P, Ackerman MJ. Clínica y genética em el síndrome de QT largo. Rev Esp Cardiol. 2007;60(7):739-52. doi: 10.1157/13108280.
8. Lankipalli RS, Zhu T, Guo D, Yan GX. Mechanisms underlying arrhythmogenesis in long QT syndrome. J Electrocardiol. 2005;38(4 Suppl):69-73.

9. Rossenbacker T, Priori SG. New insights into the longQT syndrome. Rev Esp Cardiol. 2007;60(7):675-82.

10. Schwartz PJ. The long QT syndrome. Curr Probl Cardiol. 1997;22(6):299-351.

11. Moss, AJ, Schwartz PJ, Crampton RS, Locati E, Carleen E. The long QT syndrome: a prospective international study. Circulation. 1985;71(1):17-21.

12. Zareba W, Moss AJ, Schwartz PJ, Vincent GM, Robinson $\mathrm{JL}$, Priori S, et al. Influence of genotype on the clinical course of the long-QT syndrome. N Engl J Med. 1998;339(14):960-5.

13. Kapetanopoulos A, Kluger J, Maron BJ. The congenital long QT syndrome and implications for young athletes. Med Sci Sports Exerc. 2006;38(5):816-25.

14. Keating MT, Sanguinetti MC. Molecular and cellular mechanisms of cardiac arrhythmias. Cell. 2001; 104(4):569-80.

15. Wang Q, Li Z, Shen J, Keating MT. Genomic organization of the human SCN5A gene encoding the cardiac sodium channel. Genomics. 1996;34(1):9-16.

16. Yang WP, Levesque PC, Little WA, Conder ML, Shalaby FY, Blanar MA. KVLQT1, a voltage-gated potassium channel responsible for human cardiac arrhythmias. Genet Med. 2008;10(7):545-50.

17. Neyroud N, Richard P, Vignier N, Donger C, Denjoy I, Demay L, et al. Genomic organization of the KCNQ1 $\mathrm{K}+$ channel gene and identification of C-terminal mutations in the long-QT syndrome. Circ Res. 1999; 84(3):290-7.

18. Warmke JW, Ganetzky B. A family of potassium channel genes related to eag in Drosophila and mammals. Proc Natl Acad Sci. 1994;91(8):3438-42.

19. Itoh T, Tanaka $T$, Nagai $R$, Kamiya $T$, Sawayama $T$, Nakayama T, et al. Genomic organization and mutational analysis of $H E R G$, a gene responsible for familial long QT syndrome. Hum Genet. 1998;102(4):435-9.

20. Sanguinetti MC, Jiang C, Curran ME, Keating MT. A mechanistic link between an inherited and an acquired cardiac arrhythmia: HERG encodes the I(Kr) potassium channel. Cell. 1995;81(2):299-307. 
21. George ALJ, Varkony TA, Drabkin HA, Han J, Knops JF, Finley WH, et al. Assignment of the human heart tetrodotoxin-resistant voltage-gated $\mathrm{Na}(+)$ channel alphasubunit gene $(S C N 5 A)$ to band $3 \mathrm{p} 21$. Cytogenet Cell Genet. 1995;68(1-2):67-70.

22. Gellens ME, George ALJ, Chen L, Chahine M, Horn R, Barchi RL, et al. Primary structure and functional expression of the human cardiac tetrodotoxin-insensitive voltage-dependent sodium channel. Proc Natl Acad Sci USA. 1992;89(2):554-8.

23. Wang Q, Curren ME, Splawski I, Burn TC, Millholland JM, Vanraay TJ, et al. Positional cloning of a novel potassium channel gene: KVLQT1 mutations cause cardiac arrhythmias. Nat Genet. 1996;12(1):17-23.

24. Tse WT, Menninger JC, Yang-feng TL, Francke U, Sahr $\mathrm{KE}$, Lux SE, et al. Isolation and chromosomal localization of a novel non-erythroid ankyrin gene. Genomics. 1991;10(4):858-66.

25. Splawski I, Shen J, Timothy KW, Vincent GM, Lehmann $\mathrm{MH}$, Keating MT. Genomic structure of three long QT syndrome genes: KVLQT1, HERG, and KCNE1. Genomics. 1998;51(1):86-97.

26. Chevillard C, Attali B, Lesage F, Fontes M, Barhanin J, Lazdunski $\mathrm{M}$, et al. Localization of a potassium channel gene (KCNE1) to 21q22.1-q22.2 by in situ hybridization and somatic cell hybridization. Genomics. 1993;15(1):243-5.

27. Abbott GW, Sesti F, Splawsky I, Buck ME, Lehmann $\mathrm{MH}$, Timothy KW, et al. MiRP1 forms I(kr) potassium channels with $H E R G$ and is associated with cardiac arrhythmia. Cell. 1999;97(2):175-87. doi:10.1016/ S0092-8674(00)80728-X
28. Vatta M, Ackerman MJ, Ye B, Makielski JC, Ughanze EE, Taylor EW, et al. Mutant caveolin-3 induces persistent late sodium current and Is associated with long QT syndrome. Circulation. 2006;114(20):2104-12.

29. Schwartz PJ, Priori S, Bloise R, Napolitano C, Ronchetti E, Piccinini A, et al. Molecular diagnosis in a child with sudden infant death syndrome. Lancet. 2001; 358(9290):1342-3.

30. Costa AMN, Goncalves I. Alterações cardiovasculares induzidas pelo uso de medicações psicotrópicas. Psiq Pratica Med. 2004 [acesso em 5 mar. 2009]. Disponível em: http://www.unifesp.br/dpsiq/polbr/ppm/especial06.htm.

31. Schwartz PJ, Moss AJ, Vincent GM, Crampton RS. Diagnostic criteria for the long QT syndrome: an update. Circulation. 1993;88(2):782-4.

32. Zhang L, Vincent GM, Baralle M, Baralle FE, Anson BD, Benson DW, et al. An intronic mutation causes long QT syndrome. J Am Coll Cardiol. 2004;44(6):1283-91.

33. Mitsutake A, Takeshita A, Kuroiwa A, Nakamura M. Usefulness of the Valsalva maneuver in management of the long QT syndrome. Circulation. 1981; 63(5):1029-35.

34. Viskin S. Cardiac pacing in the long QT syndrome: review of the available data and practical recommendations. J Cardiovasc Electrophysiol. 2000;11(5):593-600.

35. Marks W, Trippel DL, Keating MT. Long QT syndrome associated with syndactyly identified in females. Am J Cardiol. 1995;76(10):744-5.

36. Moss AJ, Mcdonald J. Unilateral cervico-thoracic sympathetic ganglionectomy for the treatment of long QT interval syndrome. N Engl J Med. 1971;285(16):903-4. 